\title{
CAMPO DO PODER, REFRAÇÃO POLÍTICA E LEGISLAÇÃO EDUCACIONAL: NOTAS PARA UMA DISCUSSÃO DA GESTÃO DEMOCRÁTICA NO BRASIL
}

\author{
Pablo Silva Machado Bispo dos SANTOS ${ }^{1}$
}

RESUMO: O presente artigo possui como finalidade principal analisar a Política e a Legislação Educacional a partir de um viés ainda pouco explorado, especialmente quando se trata de fenômenos intrincados e que envolvem diversas mediações, Entre estas podemos destacar as mediações jurídico-políticas e sociais. Um elemento exemplar desta ocorrência é a noção de Gestão Democrática, presente na atual Constituição Federal de 1988 (BRASIL, 1988) e na atual Lei de Diretrizes e Bases da Educação Nacional - LDB 9394/96 (BRSIL, 1996). Com vistas a analisar esta noção basilar da Educação, procuro aplicar os conceitos de Campo e Refração Política com o objetivo de examinar as referidas noções, tomando como fontes a CF/88 e a LDB 9394/96. Ao final do artigo apresento algumas decorrências desta análise.

PALAVRAS-CHAVE: Política educacional. Campo do poder e refração política. Gestão democrática.

\section{Introdução}

Uma das formas mais significativas de análise da Política Educacional diz respeito à análise de sua mediação jurídico-política. Esta interface com a Educação produz resultados muitas vezes fecundos e interessantes no que se refere à compreensão de elementos estruturantes da dimensão fundamental consubstanciada nesta área de conhecimentos. Neste sentido, merece relevo um elemento matricial da Política Educacional Brasileira: a Gestão Democrática.

A noção de Gestão Democrática possui diversas implicações para o ordenamento jurídico-político brasileiro, principalmente no que concerne à Educação. É a partir da relação entre legislação e política, bem como, na relação entre estas duas dimensões e a educação que encaminharei a análise da Gestão Democrática tanto no que se refere a sua forma legal quanto às suas “encarnações” na práxis ${ }^{2}$ educacional.

\footnotetext{
1 Doutor em Ciências Humanas. PUC- Pontifícia Universidade Católica. Professor Adjunto. UFF Universidade Federal Fluminense. Niterói - RJ - Brasil. 24220-008 - psmbsantos@ gmail.com.

${ }^{2}$ A noção de práxis é aqui entendida no sentido aristotélico do termo, qual seja, um tipo de conhecimento que é ao mesmo tempo utilizado para designar a prática do sujeito e a reflexão sobre esta mesma prática, mediadas pelo pensamento aplicado à ação.
} 
Este artigo apresenta as seguintes partes componentes: a) Referencial Teórico e conceitos estruturantes; b) CF/88 (BRASIL, 1988) e LDB 9394/96 (BRASIL, 1996) como matrizes estruturantes do Campo Político: análise retórica da refração política nos documentos oficiais. Após estas seções apresento algumas considerações finais sobre o tema, bem como indico alguns encaminhamentos para futuros estudos a partir da perspectiva adotada.

\section{Referencial teórico e conceitos estruturantes}

Se a teoria é estéril sem a prática, a prática sem a teoria não possui a consciência necessária para guiar qualquer ação investigativa. Quando a investigação possui como marca principal o recurso à análise teórica de documentos, discursos e textos, maior se torna a importância da delimitação teórica dos conceitos norteadores de tal ação. Partindo deste pressuposto, apresento abaixo os conceitos que nortearam o estudo ora apresentado e que influenciaram o olhar teórico que lanço sobre a Gestão Democrática enquanto elemento fundamental das mediações políticas do Campo Educacional.

\section{A. Campo e campo do poder}

Para Bourdieu (2001), o Campo consiste em um conceito matricial para o estudo de fenômenos sociais em esfera coletiva. O Campo seria então um conceito de geometria variável e cuja capacidade de abarcar diferentes espectros de análise se apresenta a partir do escopo de investigação do pesquisador.

Neste conceito, a influência das teorias eletromagnéticas assume papel fundamental na compreensão das estruturas sociais, com destaque para as relações entre agentes, estruturas e trajetórias, analisados de modo analógico ao de vetores representados em um plano cartesiano. Este mecanismo analítico se comporia de alguns passos indicados na sequência a seguir. Tal sequência é identificada por Lane (2006) em sua obra Bourdieu Politics. Em relação ao primeiro dos passos indica que:

Having identified those agents who qualified as 'efficient agents' in this context, Bourdieu collected a mass of biographical data about each of them, including social origin, education, career and social trajectory, before plotting that data by means of correspondence analysis. (LANE, 2006, p.78).

No tocante ao segundo dos passos da construção do instrumento analítico, seguindo o raciocínio do autor de Bourdieu Politics (LANE, 2006), temos, após a 
identificação dos "agentes eficientes" (os agentes que agem de modo diferenciado e dominante em relação ao Campo), e do conhecimento a respeito de sua trajetória social, por meio da aplicação de um tipo de análise multivariada destas posições temos as seguintes descrições:

Correspondence analysis is a form of multivariate analysis which, given a sample of, in this case, individuals, defined by a number of different variables, first identifies which of those variables are the most distinctive. The two most distinctive variables typically serve as the horizontal and vertical axes of a graph which seeks to plot, spatially, the coordinates of the 'field' in question. (LANE, 2006, p.78).

Após a definição das variáveis influenciadoras do campo e a construção dos dois eixos estruturais (e estruturantes) da análise, eixos estes correspondentes às duas variáveis com maior força de condicionamento do referido Campo (e devidamente convertidos em abscissas e ordenadas), há um terceiro passo apresentado pelo autor:

These two axes bisect one another at their mid-points, giving a graph composed of four opposing quadrants, within which the relative positions of each individual are then plotted. Secondary characteristics, less distinctive variables, also influence the position of each individual since the analysis works by giving a 'profile' of attributes to individuals and 'clustering' those individuals with similar such profiles close to one another, while those with very different profiles are situated at some distance, clustered in a different quadrant of the graph. (LANE, 2006, p.79).

Os quadrantes de análise, definidos a partir de posições negativas e positivas de acordo com suas propriedades e de acordo com as matrizes delineadas pelas variáveis mais fortes do Campo auxiliam no mapeamento dos mesmos. O trabalho de Lane (2006) representa assim um avanço importante na questão do entendimento da práxis política, em especial no que se refere à apreensão da materialidade dos agentes e dos grupos envolvidos nas disputas pelo poder em cada um destes campos.

Cabe destacar também que na perspectiva de Bourdieu (2001) o Campo é um espaço de forças, forças estas detidas pelos agentes e que se traduzem nos volumes e estruturas de capitais específicos ${ }^{3}$, coincidentes (ou não) com as estruturas definidoras

\footnotetext{
${ }^{3}$ Bourdieu (2004), ressignifica a noção de Capital, cara à teoria marxista, ampliando seu espectro. Assim, cabe indicar que existem para Bourdieu diversos tipos de capital como: Capital Cultural, Capital Político, Capital Simbólico e Capital Econômico (denominado na teoria marxista simplesmente de Capital). Cada campo possuiria um sistema de valoração de estes capitais incorporados aos agentes que nele se apresentam. A partir deste reposicionamento conceitual, Bourdieu (2001) traz novamente à cena as disputas pelo poder trazidas para diferentes instâncias sociais.
} 
do(s) campo(s) delimitado(s). Tais forças advém do que Bourdieu (2001) denomina "Campo do Poder" ou seja, um espaço social que congrega as frações dominantes, detentoras de um volume elevado de capitais condizentes com as estruturas do Campo. Tais elementos (agentes e/ou estruturas) “deformaram” a estrutura deste campo, fazendo convergir para suas posições os fluxos de capitais e de agentes cujas características distintivas se assemelham aos detentores das posições dominantes, ao mesmo tempo em que as regras e normas (especialmente estas) sociais prevalentes no referido campo deles emanam (BOURDIEU, 2004).

Os elementos mediadores destas condicionantes de trajetória do Campo, na teoria de Bourdieu (2001) são as noções de Habitus e Illusio. O Habitus, para Bourdieu (2004) seria uma matriz de comportamentos sociais incorporados ao Senso Prático do indivíduo, e que funcionaria como uma espécie de "operador simbólico" organizando no nível da prática os hábitos a partir de princípios de visão e divisão do mundo, bem como, a partir de imperativos éticos concernentes ao habitus. Cabe indicar que o habitus é adquirido socialmente, mas incorporado individualmente. Tal aquisição se dá justamente pela passagem dos agentes pelo(s) campo(s), pois é nesta passagem que a incorporação das normas e regras dos campos se dá ao nível das atitudes, visões de mundo e sistemas de classificação (SANTOS, 2007). Mas qual seria o fator que levaria a esta incorporação (quase osmótica) do habitus a partir do campo? A solução para esta mediação está em outra noção, a noção de illusio.

A noção de illusio $^{4}$ possui como significado literal "sentido do jogo", e refere-se à maneira como os agentes apropriam-se do modus operandi de determinado campo de modo a se imiscuírem nas disputas em prol dos objetivos que dão origem às mesmas e que se inscrevem tanto no nomos $^{5}$ (as regras sociais explícitas e definidoras de cada campo) e da $\operatorname{doxa}^{6}$ (tipo de conhecimento ao mesmo tempo conhecido e inconsciente e que orienta as condutas e visões de mundo dos agentes). A illusio inscreve-se de modo desigual nos agentes, incorporando-se aos seus habitus, e isto se dá a partir de um efeito

\footnotetext{
${ }^{4}$ A noção de illusio foi a estratégia conceitual de Bourdieu (2004) para explicar o sentido tácito que os participantes de determinado campo possuem a respeito de suas regras, em especial aquelas ligadas aos objetos das disputas existentes no referido Campo.

${ }^{5}$ O nomos consistiria em um "[...] princípio de visão e divisão de determinado campo particular" (ARTHUR, 2010), princípio este explícito como norma instituinte (às vezes explicitado até mesmo por meio de leis específicas e normas escritas) para os agentes presentes no Campo.

${ }^{6}$ Para Bourdieu (2004), a doxa possui um sentido diferente daquele consagrado pela filosofia platônica e que tem a ver com o sentido comum dado à experiência do mundo. Assim, tal definição pressupõe a existência de um processo de inculcação destes princípios nos agentes do referido campo subjacente às normas explícitas deste Campo, configuradas em seu nomos.
} 
de similaridade estrutural entre estes e os agentes presentes no (sub) campo do poder, de modo que tal desigualdade (estrutural, eu diria) tem a ver tanto com a origem social dos agentes quanto à sua trajetória (em sentido convergente ou divergente em relação às forças do campo).

Com base nos fatores acima expostos, concluímos esta breve explanação teórica indicando que os campos de força políticos influenciam em muito tanto as trajetórias sociais quanto os elementos definidores de suas estruturas sociais integrantes (incluídas aí as instituições), em especial no que se refere ao seu nomos institucional, de modo que, se há uma influência análoga à de um campo de forças eletromagnético sobre agentes e estruturas e que procede do (sub) campo do poder, então é possível pensar em fenômenos influenciadores destas trajetórias de agentes, bem como da incorporação deste nomos à materialidade concreta da práxis política. Eis então a gênese da discussão do conceito que denomino Refração Política.

\section{B. Refração política}

Tomando as mediações relacionais entre agentes e estruturas a partir de uma visão analógica e comparada a um campo de forças, tal como faz Bourdieu (2001), é possível pensarmos em alguns desdobramentos teórico-conceituais. Um desses diz respeito à interveniência de fatores políticos sobre o nomos de um campo, em outras palavras, diz respeito à interação entre política e legislação no que se refere à aplicabilidade desta em nível concreto, interação esta que, por ocasionar um desvio da norma em relação à letra da lei, denomino Refração Política.

Em trabalho relativo a este tema (SANTOS, 2012b) é apresentado um ensaio sobre a pertinência deste conceito para as análises empreendidas em termos de Política Educacional. Nesse mesmo trabalho de reflexão teórica aponto algumas características basilares deste conceito, em especial no que se refere à interface jurídico-política da Educação:

As relações entre Política e Legislação, bem como entre o Estado, a Legislação e a Política não podem de forma alguma ser reputadas como harmônicas, assim como, sem nenhuma sombra de dúvida, é impossível observar correspondências diretas entre estes três entes basilares dos fenômenos das sociedades contemporâneas. De modo analógico, e com vistas a fornecer elementos iniciais para analisar as já mencionadas relações, foi cunhada uma noção que utiliza como base um fenômeno físico: a refração da luz. Sobre esta noção, cabe breve descrição da mesma: a luz, ao passar de um meio para outro, 
altera sua velocidade e direção, devido à alteração de sua velocidade de propagação. (SANTOS, 2012b, p.66).

Ao ter como base este raciocínio compreendemos a necessidade de não adotar uma visão monolítica desta interface, mas antes uma visão relacional e que busque apreender as descontinuidades e conflitos existentes entre estas dimensões quando imbricadas na Educação. Assim, partindo da analogia com o fenômeno óptico da Refração da Luz, crio um constructo destinado a aferir os desvios ocorridos em relação à letra da lei quando aplicada aos diferentes contextos (e, porque não dizer, diferentes Campos) educacionais, os quais, por possuírem diversos modos de interação política ocasionariam diferentes graus de desvio (e de modificação de sua velocidade de propagação), ou, adotando a nomenclatura já mencionada, diferentes graus de refração. Trazendo a analogia para o plano concreto, associo o desvio angular às modificações de sentido sofridas pela lei ao se concretizar, bem como associo as mudanças de velocidade de propagação à efetividade (proporcional ao que seria a velocidade de propagação da luz nos meios físicos).

Com vistas a realizar tal tarefa o autor sugere, ao fim do referido ensaio, o esboço de um programa metodológico, o qual ao ser aplicado torna possível a distinção entre (ao menos alguns dentre) os diversos graus de Refração Política, recorrendo a uma combinação de diversas técnicas de pesquisa. Vamos então a este esboço de programa:

a) Analisar documentos legais e textos referentes a programas, ações e planos da política educacional. Por um lado, no que tange a corpus documentais a serem analisados, é necessário conjugar duas técnicas: 1) análise de conteúdo (com vistas a realizar o levantamento dos argumentos mais comuns e delinear o campo retórico do documento); 2) Análise retórica, com vistas a examinar a composição dos argumentos, bem como as estratégias persuasivas (relativas às proposições políticas) implicados no corpus documental já mencionado. b) Cotejar o escopo de documentos analisados com dados referentes ao momento de implementação das ações, planos e programas políticos presentes nos referidos documentos. Para que sejam colhidos tais dados, torna-se necessário a utilização de técnicas diversas de registro das ações políticas, tais como: observações etnográficas, entrevistas, questionários e leitura de periódicos relativos ao tema. Tal comparação tem como objetivo verificar as diferenças entre o texto legal e os registros relativos ao momento em que as propostas de tal texto tornam-se concretas, registrando então se houve refração política, bem como a forma concreta de que esta veio a se revestir. (SANTOS, 2012c, p.72).

Este é um programa ambicioso, e que demanda não somente um esforço concentrado e intensivo em termos de tempo e dedicação, como também requer uma 
articulação muito bem coordenada entre suas partes integrantes. Por outro lado, recordando das palavras do insigne filósofo Bachelard (1974), entendemos que é a partir das "[...] progressivas e sucessivas aproximações com o real" que refinamos os instrumentos analíticos e os modelos teóricos. Deste modo, a partir deste esboço de programa de pesquisa e dos conceitos de Campo e Refração Política, encetaremos uma análise que utiliza boa parte destes procedimentos (em especial a análise retorica e de conteúdo), restrita, porém ao escopo dos dois documentos basilares do nomos da Política Educacional brasileira no que se refere à Gestão Democrática: a CF/88 (BRASIL, 1988) e a LDB 9394/96 (BRASIL, 1996). Tal investigação, conjugada com uma análise pautada no conceito de Campo extraído da teoria de Bourdieu (2001) e adaptada ao escopo do presente trabalho objetiva tornar possível a discussão da Refração Política deste conceito.

Nesse sentido, cabe indicar que o conceito de Campo foi utilizado no afã de mapear o nomos e a doxa do referido campo, assim como delinear as variáveis mais influentes do ponto de vista jurídico-político e social, as quais por efeito de indução aglutinam e dispersam agentes e estruturas ao longo de sua extensão e em função das características do (Sub) Campo do Poder. Já o conceito de Refração Política foi utilizado no sentido de identificar as tendências de desvio em relação ao nomos do Campo estudado, procurando relacionar tais desvios à doxa deste. Assim como o conceito de Campo possibilita uma análise de largo espectro (incluindo elementos externos à letra da lei presentes no que se denomina doxa do campo), captados em função de sua influência, o conceito de Refração Política, ao conjugar alguns dos resultados desta análise com técnicas de pesquisa qualitativa como análise documental e análise retórica, possui um emprego de grande utilidade para o mapeamento do devir do Campo a partir dos já mencionados desvios em relação ao nomos do mesmo.

Na seção que se segue caracterizarei e examinarei do ponto de vista discursivo (especialmente no que tange ao aspecto retórico dos textos) os dois elementos basilares do referido nomos (CF/88 (BRASIL, 1988) e LDB 9394/96 (BRASIL, 1996)), com vistas a mapear este aspecto estrutural (e simbólico) do Campo da Política Educacional brasileira, examinado a partir da noção de Gestão Democrática.

Antes, porém, de prosseguir na análise dos elementos mencionados acima, cabe indicar o significado de alguns termos concernentes ao tema que se apresenta em tela. Deste modo, vamos a uma breve explanação acerca das definições de Política Educacional e de Gestão Educacional abordadas neste trabalho. 
Deste modo, levando em consideração a associação entre os conceitos de Campo e de Refração Política, temos finalmente condições de analisar os documentos legais que são objeto deste trabalho: a CF/88 (BRASIL, 1988) e a LDB 9394/96 (BRASIL, 1996).

\section{A CF/88 (BRASIL, 1988) e a LDB 9394/96 (BRASIL, 1996) como matrizes estruturantes do campo político: analisando o campo do poder e a refração política}

O Ordenamento Jurídico Brasileiro possui como fulcro da legislação a sua Constituição Federal (BRASIL, 1988). Do ponto de vista jurídico ela vem a ser a carta magna, a regulamentação máxima, matriz de toda a legislação que lhe sucede, sendo portanto um elemento nomotético de caráter instituidor. Não se pode esquecer, no entanto, que do ponto de vista Político, a CF/88 (BRASIL, 1988) é ao mesmo tempo uma Política Pública Instituinte, e seu poder de instituição se coloca na medida em que institui o ordenamento jurídico e contribui para a delimitação dos limites normativos do Estado, e, ao mesmo tempo, devido a este mesmo ordenamento e às relações entre Estado e Sociedade acaba por vir a ser instituída no âmbito desta mediação (SANTOS, 2012a). Desta forma, é por meio desta relação dialética entre a função instituidora e a função instituinte que iremos apreender seu caráter normativo e ao mesmo tempo nãomonolítico, e sua consequente conexão com o devir da sociedade (ao menos nas partes deste documento que podem ser transformadas por não consistirem em Cláusulas Pétreas).

A partir deste fulcro de legislação, o nomos do Campo da Política Educacional emana seu poder regulamentador em direção a um elemento regulatório específico e que vem a ser a chave de sua existência jurídica, a Lei de Diretrizes e Bases da Educação Nacional (BRASIL, 1996). A LDB 9394/96 (BRASIL, 1996) complementa a CF/88 (BRASIL, 1988) e detalha os artigos 205 a 214 desta, contendo uma estrutura (em muitas passagens) ambígua e cuja base material assenta sobre 92 artigos.

Adiante veremos como a Gestão Democrática é tratada na CF/88 (BRASIL, 1988) e na LDB 9394/96 (BRASIL, 1996) a partir da análise dos discursos contidos nos documentos legais no que diz respeito ao tema aludido anteriormente. De acordo com a proposta deste trabalho, será feita uma análise retórica destes documentos oficiais, análise esta que consiste em mapear o conteúdo do texto constitucional e do texto da LDB 9394/96 (BRASIL, 1996), em especial no que se refere à temática da Gestão Democrática, o que foi realizado a partir da combinação de duas técnicas analíticas: $a$ ) 
Análise de Força Discursiva ${ }^{7}$ (REBOUL, 2006): com este procedimento viso ao desenvolvimento de uma "exegese" intratextual, na qual procuro verificar em que medida o topos $^{8}$ contido no setor do texto é organizado enquanto unidade de enunciado discursivo; b) Análise de Campo Retórico ${ }^{9}$ (PERELMAN, 2001): na qual procuro correlacionar o conteúdo deste em função do teor de todo o documento (já captado em análises prévias do mesmo, realizadas por outros autores), o que é feito de modo a correlacionar o conteúdo dos topoi (elementos fortes do discurso) ao contexto de produção do referido discurso.

\section{A. A Gestão Democrática na LDB 9394/96 (BRASIL, 1996)}

A LDB (BRASIL, 1996), nos artigos 3, 14, 15, 21 e 56 aborda a questão da Gestão Democrática. Nestes artigos, esta matéria é tratada de formas diversas e aplicada a diversas instâncias de regulamentação. A seguir faremos uma exposição dos referidos artigos, seguida de nova aplicação das técnicas de análise retórica empregadas anteriormente.

Vamos aos excertos da LDB (BRASIL, 1996) que tratam desta temática, comecemos pelo Inciso VIII do Artigo 3: “[...] O ensino será ministrado com base nos seguintes princípios [...] VIII - gestão democrática do ensino público, na forma desta Lei e da legislação dos sistemas de ensino".

Adiante, em outra seção do texto legal, vejamos o que diz o artigo 14:

${ }^{7}$ Reboul (2006) indica a possibilidade de ser efetuada a análise de discursos a partir da força interna de cada uma das palavras, procurando identificar quais dessas possuem mais força no sentido de determinar (ou condicionar) os objetivos intrínsecos ao discurso, bem como os elementos subjacentes a estes e que muitas vezes não se dariam a conhecer pela mera leitura dos entimemas (premissas enunciadas somente em parte, mas que pelo contexto geral do discurso induzem de modo sub-reptício o interlocutor a adotar a posição do enunciador do discurso) neles contidos. Em suma, do mesmo modo como a Análise de Campo Retórico possui como foco privilegiado o trabalho intertextual, a Análise de Força Discursiva possibilita a realização de uma análise intratextual dos discursos.

${ }^{8}$ Aristóteles (2000) indica que os discursos podem ser organizados a partir de alguns núcleos de força significante, os quais são identificados como topos (no singular) e topoi (quando empregados no plural). A partir desta distinção os elementos discursivos presentes em textos e na fala podem ser analisado com base nestes fulcros de sentido e significado que estruturam a argumentação e os diálogos em geral.

${ }^{9}$ A esse respeito, Perelman (2001) indica que existe um tipo de análise retórica que procura analisar os textos a partir do modo como são produzidos no âmbito de unidades maiores de sentido, mas ainda assim pertinentes ao mesmo texto, tomado em sua integralidade. Tal análise é denominada Análise de Campo Retórico e inclui em seus elementos de compreensão a ideia de que o texto enfocado se destina a determinado auditório e que é composto em função deste, com vistas a influenciar o mesmo. Assim, está colocada de modo subjacente a premissa de que há um diálogo (mesmo que de modo implícito) e que tal diálogo permeia todo e qualquer texto, o que viria a ressaltar o caráter dialético da retórica, percebido já desde os diálogos de Platão. 
Art. 14. Os sistemas de ensino definirão as normas da gestão democrática do ensino público na educação básica, de acordo com as suas peculiaridades e conforme os seguintes princípios: I participação dos profissionais da educação na elaboração do projeto pedagógico da escola; II - participação das comunidades escolar e local em conselhos escolares ou equivalentes. (BRASIL, 1996).

Por último, no Art. 56 da LDB (BRASIL, 1996) temos a Gestão Democrática colocada em relação à Educação Superior nos seguintes termos: “[...] Art. 56. As instituições públicas de educação superior obedecerão ao princípio da gestão democrática, assegurada a existência de órgãos colegiados deliberativos, de que participarão os segmentos da comunidade institucional, local e regional”.

No caso da LDB 9394/96 (BRASIL, 1996), com vistas a tornar mais concatenada e clara a análise retórica, será invertida a ordem das técnicas, de modo que iniciaremos com a técnica de Análise do Campo Retórico, sendo depois aplicada a técnica de Análise da Força Discursiva. A razão que motiva tal inversão está no fato de que a LDB 9394/96 (BRASIL, 1996) é uma lei que complementa e detalha a CF/88 (BRASIL, 1988), e por isso é impossível pensar na mesma de modo isolado, sem considerar que a influência constitucional faz parte do próprio cerne da LDB. Adiante apresento a análise do Campo Retórico desta lei integrante do nomos do Campo investigado no presente trabalho.

A Análise do Campo Retórico da LDB 9394/96 (BRASIL, 1996) se inicia a partir de características da CF/88 (BRASIL, 1988), as quais possuem correspondência com a Lei Maior da Educação brasileira. Tais características gerais se espelham devido ao já mencionado fato de que a LDB (BRASIL, 1996) possui uma característica de Lei Complementar em relação à CF/88 (BRASIL, 1988). Dentre tais características, duas merecem destaque: a) Tanto a CF/88 (BRASIL, 1988) quanto a LDB 9394/96 (BRASIL, 1996) trabalham com uma perspectiva de responsabilização quanto a esta matéria; b) Tanto a CF/88 (BRSIL, 1988) quanto a LDB 9394/96 (BRASIL, 1996), devido à influência liberal de (ao menos alguns) de seus formuladores não regulamenta alguns aspectos cruciais (até pelo fato de ser a LDB 9394/96 (BRASIL, 1996) um instrumento jurídico de imenso potencial normativo). Além desses elementos, cabe destacar uma característica geral da LDB (BRASIL, 1996): a contradição entre regulamentação e flexibilização. Vejamos caso a caso em que implica a existência destes elementos imbricados no Campo Retórico da LDB (BRASIL, 1996). 


\section{B. A Gestão Democrática e a doxa do Campo: fatores políticos, sociais e}

\section{culturais influenciadores}

De modo a exemplificar alguns dos fatores políticos e culturais que intervém na construção de uma doxa política relativa à Gestão Democrática e que se verifica no âmbito de instituições escolares e sistemas de ensino, recorro ao trabalho de pesquisa desenvolvido por Mendonça (2001) sobre o tema. Vejamos um excerto de seu artigo, fruto de tal pesquisa:

Vários estudos sobre gestão democrática abordam a participação como temática principal. Ao abordar aspectos da gestão democrática do ensino público ligados à participação, foi possível constatar que, ao contrário do que se idealiza sobre a convivência entre membros da comunidade escolar, os mecanismos adotados pelos sistemas não lograram pôr termo à guerra entre segmentos. Diretores, professores e funcionários, com prevalência dos primeiros, ainda monopolizam os foros de participação. A escola pública ainda é vista pelos usuários como propriedade do governo ou do pessoal que nela trabalha. $\mathrm{O}$ professor comporta-se como dono do seu cargo, dos alunos e de suas classes. O diretor funciona como guardião dessa concepção, evitando interferências de servidores e de pais. As legislações têm funcionado como mecanismos reguladores dessa prevalência, uma vez que impõem critérios de proporcionalidade na participação aos segmentos organizados da comunidade escolar. Isso não impede, no entanto, que permaneçam existindo comportamentos e atitudes de dominação dos docentes sobre os demais membros, sob argumentos que, em geral, se baseiam em questões ligadas à competência pedagógica. Apesar das várias tentativas legais de correção das distorções que privilegiam os segmentos docente e administrativo, observam-se algumas legislações que chegam a legitimar a restrição à participação dos pais e responsáveis. (MENDONÇA, 2001, p.87, grifo nosso).

Conforme é possível perceber, a doxa do Campo condicionado pelos documentos oficiais enseja a uma ação concreta dissonante com os princípios do que se poderia chamar gestão democrática. Neste sentido, o patrimonialismo subjacente à cultura política presente em escolas e sistemas de ensino seria elemento condicionante de práticas que vão muito mais na direção da legitimação da ação política autoritária do que na direção de um aumento significativo da participação paritária nos processos decisórios.

De todo modo, cabe mencionar o fato de que, ao menos em nível formal, estruturas de participação democrática da sociedade civil vêm sendo construídas no âmbito da Educação. Assim, deve ser salientado o fato de que um dos efeitos mais claros da adoção (no âmbito legal) da prática da Gestão Democrática diz respeito à instituição de conselhos nas escolas e entes federativos, conselhos estes nos quais as 
decisões colegiadas são tomadas por representantes de diversos segmentos da sociedade (CURY, 2007).

Ainda no que diz respeito às estruturas formais de Controle Social ${ }^{10}$, Macedo (2010) nos alerta para o fato de que muitas destas estruturas envolvidas no que se convencionou denominar Gestão Democrática não funcionam como deveriam. Em especial deve ser mencionado o fato de que muitos dos conselhos (sobretudo quando se trata de conselhos envolvidos na gestão de recursos financeiros) funcionam de modo precário (com reuniões irregulares e sem a devida articulação com a sociedade civil) ou existem meramente no plano formal (com os representantes indicados pelos poderes políticos locais, os quais muitas vezes sequer comparecem às reuniões). Deste modo, partindo desta premissa, tudo leva a crer que para além da existência formal de mecanismos construídos para a participação da sociedade civil, tal participação, por um efeito de refração política (que merece uma investigação mais detalhada quanto à temática específica dos conselhos) acaba vindo a reforçar as estruturas políticas já existentes em nível local (especialmente em nível municipal), o que contribuiria sobremaneira para a manutenção de práticas políticas que não tem a ver com a Gestão Democrática (como o apadrinhamento político, por exemplo).

\section{Considerações Finais}

Após o processo de análise conceitual e consequente aplicação do instrumento de pesquisa construído com esta finalidade (e devidamente explicitado em seção anterior deste trabalho), foi possível chegar a algumas considerações, as quais, muito antes de esgotar o potencial heurístico da realidade (pois não creio ser possível a existência de uma pesquisa que se pretenda "final" sobre qualquer tema) pois isto fugiria do escopo de uma investigação científica (e, sem dúvida alguma, dos objetivos deste artigo), ainda assim trazem contribuições que considero relevantes para futuros estudos e pesquisas a respeito deste tema.

${ }^{10} \mathrm{O}$ Controle Social se insere no âmbito das políticas de responsabilização já mencionadas, e encontra eco sobretudo em dispositivos legais como o Decreto 6.094/07 (BRASIL, 2007), o qual fixa entre as metas do Plano de Desenvolvimento da Educação, a presença de Conselhos Escolares em todas as escolas até o ano de 2020, conselhos estes compostos não somente por alunos, professores e funcionários das escolas mas integrando também representantes de entidades sindicais associações de moradores e demais atores da sociedade civil. 
Conforme foi possível perceber, a Gestão Democrática corresponde a uma expressão polissêmica cujo sentido é, de certa forma, condicionado e determinado em essência pela CF/88 (BRASIL, 1988) e pela LDB 9394/96 (BRASIL, 1996) (tal como apontado anteriormente) ${ }^{11}$. Para além de seu formato legal e de sua inserção no ordenamento jurídico-político brasileiro, cabe destacar que a Gestão Democrática encontra no âmbito dos programas governamentais e também na prática pedagógica das escolas diversas "encarnações", as quais correspondem a variações possíveis dentro do escopo deste conceito. Partindo deste princípio, entendemos que a Gestão Democrática sore influências diversas da Política Educacional Brasileira em sentido lato, de maneira que se coaduna de modo coerente com o conceito de Refração Política (SANTOS, 2012a), na medida em que podemos observar que muitas vezes a noção de Gestão Democrática presente no âmbito dos programas governamentais acaba por ter seu sentido modificado, guardando alguma distância entre o seu sentido expresso nos textos dos documentos oficiais e, a prática dos agentes que se encontram presentes no Campo.

Face ao exposto e tomando como base a análise de documentos oficiais como a LDB 9394/96 (BRASIL, 1996), torna-se claro que o desafio da implantação da Gestão Democrática no que tange à Política Educacional Brasileira comporta (no mínimo) duas etapas gerais em sua efetiva construção: a) Construção dos mecanismos em que a participação de todos os envolvidos na dinâmica da gestão (em todos os níveis da política educacional) possam acompanhar e atuar em nível decisório; b) Promover a participação e utilização consciente dos referidos mecanismos.

O primeiro destes desafios encontra-se em parte consolidado, na medida em que, no nível dos programas governamentais, e no nível dos documentos legais (sobretudo na CF/88 (BRASIL, 1988) e na LDB 9394/96 (BRASIL, 1996)) a Gestão Democrática é instituída como princípio da administração pública, e regulamentado por toda a legislação infraconstitucional que, instituiu conselhos de educação diversos como o Conselho Nacional de Educação (CNE), Conselhos Estaduais de Educação (CEE’s) e Conselhos Municipais de Educação (CME's), isto sem contar os diversos conselhos de Controle Social (MACEDO, 2010) como os Conselhos do FUNDEB, Conselho Escolar, Conselho de Alimentação Escolar (CAE) que, em diferentes instâncias da administração

\footnotetext{
${ }^{11}$ Não é demais insistir no fato de que a exigência da criação de conselhos integrados por membros que representam a sociedade civil consiste em uma implantação formal da Gestão Democrática, na medida em que são construídos os mecanismos necessários a seu exercício em nível concreto, porém a mera existência de tais mecanismos garante tanto a sua efetivação quanto o fato de existirem bancos garantes às pessoas o acesso aos recursos financeiros e serviços que existem nos mesmos.
} 
pública fornecem a possibilidade da sociedade civil realizar a fiscalização do funcionamento das políticas desenvolvidas pelas diversas instâncias governamentais.

No que diz respeito ao segundo dos desafios, entretanto, há ainda muito a realizar, na medida em que os resquícios do autoritarismo, a ação de nepotismos e diversas formas de favorecimento, além do patrimonialismo que muitas vezes subjaz às práticas político-administrativas dos gestores educacionais (em nível institucional e local, sobretudo). Estes são fatores acabam por reduzir a influência das supracitadas estruturas de participação (MENDONÇA, 2001), contribuindo diversas vezes para a manutenção de relações viciadas de poder político, fundadas em formas diversas de clientelismo.

Devido a este cenário, que se situa em um processo de transição entre distintos modelos de sociedade (do autoritarismo para a democracia participativa) e de modelos de gestão concernentes a estes modelos (da Gestão Burocrática para a Gestão Democrática) é possível compreender o momento atual da Política Educacional Brasileira (especialmente no que compete à Gestão Democrática) como um momento de intensas lutas e mudanças pela afirmação de um modelo de democracia participativa nunca antes vivenciado no âmbito da Educação Nacional. Por último, mas nem por isso menos importante, cabe tecer duas últimas considerações.

A primeira se liga ao fato de que a dimensão jurídico-política é condicionada por documentos legais, mas a eles não se circunscreve, de modo que a ação dos agentes em comparação com o nomos instituído é elemento que demanda uma pesquisa muito mais extensiva do que a efetuada no âmbito deste artigo. Assim, como encaminhamento para futuros estudos, cabe trazer mais próximo da empiria tal viés de análise, o que se torna possível mediante ao recurso a entrevistas, questionários e técnicas de observação de cunho etnográfico envolvendo os agentes que circulam no Campo desenhado pelas instituições de ensino, redes de ensino e leis que dizem respeito à Gestão Democrática.

A segunda das considerações se refere ao fato de que estudos desta natureza contribuem não somente para a ampliação do arcabouço de resultados empíricos acerca de temas e questões controversas (como o caso da Gestão Democrática) mas também para que conceitos como Campo e Refração Política possam ser revistos e adaptados às múltiplas e fluidas realidades condicionadas pelas lutas e debates políticos ocorridos no momento da formulação das leis e de sua implantação. Penso que somente com esforços deste tipo, combinando empiria e teoria, será possível conseguir a precisão e rigor necessários para a abordagem de fenômenos complexos como a implantação da Gestão 
Democrática nas instituições educacionais (mas também nos sistemas de ensino) de um País que somente nos últimos anos pôde ter acesso à democracia.

\section{FIELD OF POWER, REFRACTION POLICY AND EDUCATION LAW: NOTES FOR A DISCUSSION OF THE DEMOCRATIC MANAGEMENT IN BRAZIL}

ABSTRACT: This paper has as main purpose to analyze the Educational Policy and Legislation from a bias still underexplored, who explores the mediations between these legal and political and social analysis of this process becomes even more complex. A example of this occurring element is the notion of democratic management, present in the current Constituição Federal do Brasil (CF/88) (BRASIL, 1988) and the current Lei de Diretrizes e Bases da Educação Nacional (LDB 9394/96) (BRASIL, 1996). In order to analyze this basic notion for the education, try to apply the concepts of Field and Refraction Policy in order to examine these notions, taking as sources the CF/88(BRASIL, 1988) and LDB 9394/96 (BRASIL, 1996). At the end of the article I present some consequences of this analysis.

KEYWORDS: Education policy. Field of power and policy refraction. Democratic management.

\section{REFERÊNCIAS}

ARISTÓTELES. Arte retórica. Tradução de A. P. de Carvalho. Rio de Janeiro: EDIOURO, 2000.

ARTHUR, C. Financial literacy in Ontario: neoliberalism, Pierre Bourdieu and the citizen. Journal for Critical Education Policy Studies, Ontário, v.9, n.1, p.188-222, 2010.

BACHELARD, G. O racionalismo aplicado. Rio de Janeiro: Jorge Zahar, 1974.

BRASIL. Constituição (1988). Constituição da República Federativa do Brasil: promulgada em 5 de outubro de 1988 [online]. Disponível em:

<http://www.dji.com.br/constituicao_federal/cf205a214.htm>. Acesso em: 10 fev. 2013.

Ministério da Educação. Decreto 6.094/07 de 24 de Abril de 2007. Institui o compromisso todos pela educação. Brasília: Senado Federal, 2007. Disponível em: <http://www.planalto.gov.br/ccivil_03/_ato20072010/2007/decreto/d6094.htm>. Acesso em: 12 mar. 2014.

. Ministério da Educação. Lei 9394/96 de 20 de Dezembro de 1996. Lei de Diretrizes e Bases da Educação Nacional. Brasília: Senado Federal, 1996. Disponível em: <www.planalto.gov.br/ccivil_03/leis/L9394.htm>. Acesso em: 5 mar. 2014. 
BOURDIEU, P. Fieldwork in philosophy. In: . Coisas ditas. São Paulo:

Brasiliense, 2004. p.15-48.

O poder simbólico. Rio de Janeiro: Bertrand Brasil, 2001.

CURY, C. R. J. A gestão democrática na escola e o direito à educação. Revista

Brasileira de Política e Administração da Educação, [S.1.], v.23, n.3, p 483-495, set./dez. 2007.

LANE, J. Bourdieu politics. New York: Routledge, 2006.

MACEDO, D. B. S. Acompanhamento e controle social no Brasil. 2.ed. São Paulo: Xamã, 2010.

MENDONÇA, E. F. Estado patrimonial e gestão democrática do ensino público no Brasil. Educação \& Sociedade, Campinas, v.22, n.75, p.93-123, ago. 2001.

PERELMAN, C. Tratado de argumentação: a nova retórica. 11.ed. São Paulo: Martins Fontes, 2001.

REBOUL, O, Introdução à retórica. Rio de Janeiro: Jorge Zahar, 2006.

SANTOS, P. S. M. B. Guia prático da política educacional no Brasil. Ações, planos, programas e impactos. São Paulo: CENGAGE, 2012a.

Questões polêmicas de política e legislação educacional. Curitiba: Editora CRV, 2012b.

Sobre a sociologia educacional de Pierre Bourdieu: primeiros conceitos [online]. 2007. Disponível em: <http://pt.shvoong.com/socialsciences/education/1100054-sobre-sociologia-educacional-pierrebourdieu/>. Acesso em: 7 fev. 2013.

Sobre o conceito de refração política: mais uma chave dos segredos das ciências humanas. Revista Espaço Acadêmico, Maringá, v.12, n.137, p.67-75, 2012c. 